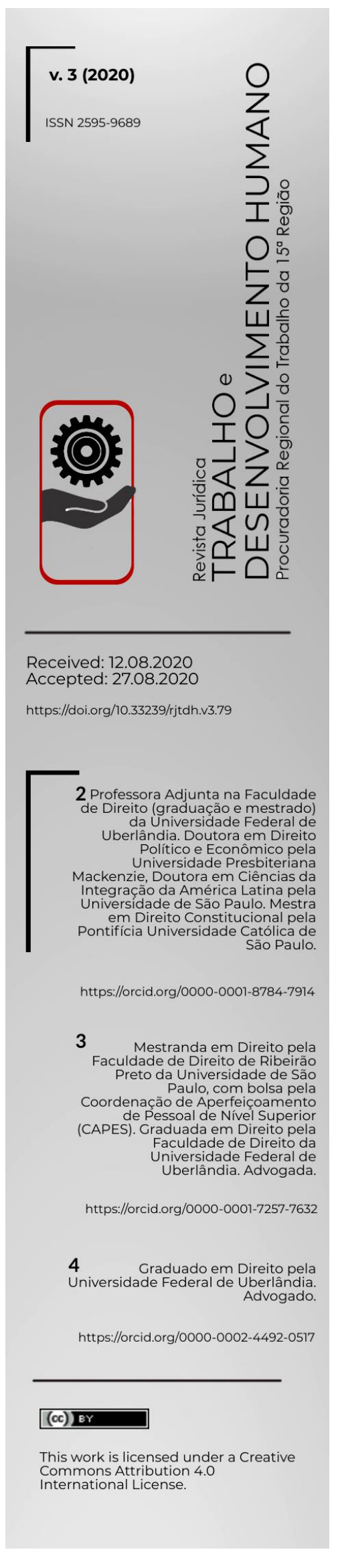

\title{
O papel dos sindicatos e o (des)amparo aos direitos laborais dos entregadores de aplicativo frente à pandemia de
} Covid-19 1

\author{
The role of trade unions and the labor rights (de)protection of application \\ delivery workers in front of the Covid-19 pandemic
}

El papel de los sindicatos y la (de)protección de los derechos laborales de los trabajadores de entrega de aplicaciones frente a la pandemia de Covid-

\author{
Juliane Caravieri Martins ${ }^{2}$ \\ Catharina Lopes Scodro ${ }^{3}$ \\ Felipe Melo de Souza ${ }^{4}$
}

\begin{abstract}
RESUMO
No âmbito do Direito do Trabalho, o direito de associação dos trabalhadores e, portanto, de organização em entidades sindicais apresenta grande importância para garantia de melhores condições de vida, de trabalho e de salário, por exemplo, por conferir poder de barganha. $\mathrm{Na}$ atualidade, o cenário de pandemia de COVID-19 e de adoção de medidas de distanciamento social propiciou o reconhecimento da atividade desempenhada pelos entregadores vinculados aos aplicativos de delivery como essencial, evidenciando, por conseguinte, o contexto de precarização e desregulamentação. Esse artigo, a partir do método dedutivo e da técnica de pesquisa bibliográfico-documental, propõe a análise do direito de associação dos trabalhadores e a função dos sindicatos, especialmente durante a pandemia no Brasil, no que tange à garantia dos direitos dos entregadores vinculados aos aplicativos de delivery. Para tanto, abordará os seguintes tópicos: 1. O Direito de livre associação e os sindicatos - Reveses ante a Reforma Trabalhista de 2017 no Brasil; 2. Pandemia de COVID-19, instrumentos legislativos e reflexos no mundo do trabalho; 3 . A atuação do sindicato na promoção de direitos dos entregadores de aplicativos em tempos de coronavírus.
\end{abstract}

PALAVRAS-ChAVE: Pandemia de COVID-19. Sindicatos. Direito Coletivo do Trabalho. Entregadores de aplicativos.

\section{ABSTRACT}

In the scope of Labor Law, the right of workers' association and, therefore, of organization in union entities, has great importance for guaranteeing better living, working and salary conditions, for example, by conferring bargaining power. Currently, the pandemic scenario of COVID-19 and the adoption of measures of social distancing provided the recognition of the activity performed by deliverers of applications as essential, evidencing the context of precariousness and deregulation. This article, based on the deductive method and the bibliographic-documental research technique, proposes the analysis of the right to association of workers and the role of trade unions, especially during the pandemic in Brazil, with regard to guaranteeing the rights of application delivery workers. To this end, it will address the following topics: 1 . The right to freedom of association and trade unions - Setbacks from the Labor Reform in Brazil (2017); 2. COVID-19 pandemic, legislative instruments and impacts on

\footnotetext{
${ }^{1} \mathrm{O}$ presente artigo é fruto das atividades do Grupo de Pesquisa "Reformas Trabalhistas e os Retrocessos no Mundo do Trabalho: Perspectivas para a América Latina", vinculado a Universidade Federal de Uberlândia e cadastrado no diretório dos grupos de pesquisa do Conselho Nacional de Desenvolvimento Científico e Tecnológico (CNPq).
} 
the world of work; 3. The union's role in promoting the rights of application deliverers in times of coronavirus.

KEYWORDS: COVID-19 pandemic. Trade unions. Collective Labor Law. Application delivery workers.

\section{RESÚMEN}

En el ámbito de la legislación laboral, el derecho de asociación de trabajadores y, por lo tanto, de organización en entidades sindicales, es de gran importancia para garantizar mejores condiciones de vida, trabajo y salario, por ejemplo, al conferir poder de negociación. Actualmente, el escenario de pandemia de COVID-19 y la adopción de medidas de distanciamiento social proporcionaron el reconocimiento de la actividad realizada por los repartidores vinculados a las aplicaciones de entrega como esenciales, mostrando así el contexto de precariedad y desregulación. Este artículo, basado en el método deductivo y la técnica de investigación bibliográfica-documental, propone análisis del derecho de asociación de los trabajadores y el papel de los sindicatos, especialmente durante la pandemia en Brasil, con respecto a garantizar los derechos de las personas de entrega vinculadas a aplicaciones de entrega. Con este fin, abordará los siguientes temas: 1. El derecho a la libre asociación y sindicatos: contratiempos de la Reforma Laboral de 2017 en Brasil; 2. La pandemia del COVID19, instrumentos legislativos y efectos en el mundo del trabajo; 3 . El papel de la Unión en la promoción de los derechos de los proveedores de aplicaciones en tiempos de coronavirus.

PALABRAS-CLAVE: Pandemia del COVID-19. Sindicatos. Derecho laboral colectivo. Trabajadores de entrega de aplicaciones.

\section{INTRODUÇÃO}

Na seara internacional, o desenvolvimento do direito de associação dos trabalhadores se deu a partir do capitalismo industrial, nas mobilizações por melhores condições de vida, trabalho e salário do operariado. O reconhecimento, o fortalecimento e a institucionalização do direito e, portanto, da liberdade de associação sindical, deu-se posteriormente, pelo contexto de desenvolvimento do Direito do Trabalho, de constitucionalização dos direitos sociais e de internacionalização dos direitos humanos após a Segunda Guerra Mundial.

A despeito da trajetória de reconhecimento do direito de associação sindical e de sua importância na garantia do poder de negociação e de garantia de direitos pela classe trabalhadora, no Brasil, o Direito Coletivo do Trabalho atravessa turbulências, especialmente em razão do enfraquecimento das entidades sindicais vivenciado após a Reforma Trabalhista de 2017.

Esse artigo, a partir do método dedutivo ${ }^{2}$ e da técnica de pesquisa bibliográficodocumental, propõe a análise do direito à associação dos trabalhadores e a função dos sindicatos, especialmente durante a pandemia e a emergência em saúde pública oriunda da COVID-19 no Brasil

\footnotetext{
${ }^{2}$ MARCONI, Marina de Andrade; LAKATOS, Eva Maria. Metodologia científica. 5. ed. São Paulo: Atlas, 2003. p. 91.
} 
(2020), enfocando especialmente a garantia dos direitos dos entregadores vinculados aos aplicativos de delivery, reconhecidos como trabalhadores essenciais durante esse período de excepcionalidade. Para tanto, a abordagem se dará nos seguintes tópicos: 1 . 0 direito de livre associação e os sindicatos - Reveses ante a Reforma Trabalhista de 2017 no Brasil; 2. Pandemia de COVID-19, instrumentos legislativos e reflexos no mundo do trabalho; 3. A atuação do sindicato na promoção de direitos dos entregadores de aplicativos em tempos de coronavírus.

Ao final, almejou-se contribuir para o enriquecimento das discussões sobre o papel e atuação dos sindicatos no Brasil na atualidade, especialmente em tempos pandêmicos que aceleram o crescente processo de desconstrução dos direitos sociais trabalhistas.

1. O direito de livre associação e os sindicatos - Reveses ante a Reforma Trabalhista de 2017 no Brasil

O direito de associação sindical está umbilicalmente relacionado ao trabalho assalariado que se consolidou a partir da primeira Revolução Industrial na Europa e depois se expandiu para o mundo no contexto do capitalismo industrial. Não se pode olvidar que, ao longo dos séculos, o trabalho sempre esteve associado a uma atividade penosa que não traria felicidade ao homem, sendo relegado aos escravos no mundo antigo (sistema escravista), aos servos no medievo (sistema feudal) e ao proletariado na era moderna (sistema capitalista). Conforme preleciona Nicola Abbagno ${ }^{3}$ o conceito de trabalho implica "1) a dependência do homem [...] em relação à natureza: o que constitui a necessidade; 2 ) a reação ativa a essa dependência, constituída por operações mais ou menos de elevado esforço, sofrimento ou cansaço, que constitui o custo humano do trabalho".

A concepção do trabalho como atividade que garantiria a subsistência humana ganhou novos contornos a partir do capitalismo industrial ao se consolidar como trabalho assalariado porque os trabalhadores "livres" venderiam sua força de trabalho em troca de salário para a subsistência. Então, ganhou força o direito de associação, em especial sindical, para a defesa de

\footnotetext{
${ }^{3}$ ABBAGNANO, Nicola. Dicionário de filosofia. Trad. Ivone Castilho Benedetti. 5. ed. São Paulo: Martins Fontes, 2007, p. 1147-1148. 
Revista Jurídica Trabalho e Desenvolvimento Humano

Procuradoria Regional do Trabalho da 15a Região

melhores condições de trabalho, de vida e de renda aos trabalhadores, viabilizando a organização dos sindicatos.

A partir do capitalismo industrial, se consolidou o trabalho assalariado como "engrenagem" do processo de produção, amparado num contrato de trabalho regulado pelo Direito Civil, de cunho liberal e individualista, que considerava as partes contratantes como indivíduos formalmente iguais com plena autonomia privada de vontade para firmar pactos. Porém, esse trabalho assalariado não é exatamente "livre" porque há desigualdades profundas (sociais, econômicas e de vida), entre os contratantes, a saber, o operariado e a burguesia.

O capitalismo industrial impôs um processo produtivo altamente impessoal ditado pelo ritmo de trabalho das máquinas e, posteriormente, da tecnologia. A habilidade individual não era mais necessária, pois a produção mecanizada exigia regularidade absoluta dos movimentos humanos, de modo que o trabalhador passou a ser apêndice de equipamentos e instrumentos de produção.

Mulheres e crianças aderiram ao trabalho nas fábricas, recebendo salários inferiores aos dos homens para a execução do mesmo tipo de tarefa. A jornada de trabalho variava de quatorze a dezoito horas diárias, com pouquíssima interrupção para descanso e refeição. As crianças chegavam nas fábricas pela manhã e as deixavam à noite, caindo exaustas ao final do expediente. Nesse sentido, Edward PalmerThompson preleciona que "nas fábricas, a força de trabalho infantil e juvenil crescia a cada ano; em diversos ofícios 'indignos' ou relacionados com o trabalho externo, seu trabalho tornava-se mais intenso, e a jornada, mais longa" 4.

Quando grávidas, as operárias trabalhavam até a última semana de gestação, retornando à fábrica três semanas ou menos após o parto, pois temiam perder o emprego precário. As mães operárias mantinham as crianças pequenas quietas mediante o uso de "chupetas sujas feitas de trapos, atadas a um pedaço de pão embebido em leite e água, e podiam ser vistas, entre os dois ou três anos de idade, correndo pelos corredores das fábricas, com estes trapos na boca" 5 .

\footnotetext{
${ }^{4}$ THOMPSON, Edward Palmer. A formação da classe operária inglesa: a maldição de adão. Trad. Renato Busatto Neto e Claudia Rocha de Almeida. v. 2, 2. ed. Rio de Janeiro: Paz e Terra, 1997, p. 202.

${ }^{5}$ THOMPSON, Edward Palmer. A formação da classe operária inglesa: a maldição de adão. Trad. Renato Busatto Neto e Claudia Rocha de Almeida. v. 2, 2. ed. Rio de Janeiro: Paz e Terra, 1997, p. 197.
} 
Revista Jurídica Trabalho e Desenvolvimento Humano

Procuradoria Regional do Trabalho da 15a Região

A fim de debelar esse quadro de miséria e degradação humana, em 1848, houve revoltas sequenciais em diversos países europeus como a Revolução de 1848, chamada de "Primavera dos Povos", oriunda do estado de miséria em que as pessoas se encontravam, especialmente os trabalhadores. Influenciadas pela "necessária luta de classes entre proletariado e burguesia", apregoada por Karl Marx e Friederich Engels desde o Manifesto do Partido Comunista (1848), essas revoltas se espalharam pelo Europa como rastilho de pólvora6 ${ }^{6}$ Entretanto, outras vozes também se levantaram contra a exploração do operariado, tais como Robert Owen (1771-1858), empresário do País de Gales, que incentivou a associação dos operários (as trade unions), fortalecendo o movimento sindical. Segundo Arnaldo Sussekind:

[...] o ressurgimento, sob várias formas, das trade unions inglesas e das batalhas que travaram para a obtenção de leis imperativas de proteção ao trabalho, [...] levou o Parlamento Britânico a revogar, em 1824, proibições contidas nas leis de 1799 e 1800 e a tolerar o sindicalismo, embora sem atribuir personalidade jurídica às trade unions. Estas se desenvolveram desde então, ampliaram a luta, por vezes violenta, pela conquista de direitos; em 1833, sob a inspiração de Owen, fundaram a "União Nacional Consolidada" (uma confederação sindical que chegou a reunir meio milhão de associados), e deflagaram uma série de greves, num movimento denominado "cartismo", porque visava a conquistar a "Carta Constitucional do Trabalho". Em 1847, coroando uma campanha que levou ao Parlamento inglês uma petição pesando 300 quilos e contendo dois milhões de assinaturas, na qual as trade unions reivindicavam a lei das oito horas de trabalho, foi aprovada a primeira lei limitadora da jornada de trabalho, afinal fixada em 10 horas. O sindicalismo, iniciado na Inglaterra, logo se expandiu para a França, Alemanha, Itália, Estados Unidos e outros países industrializados. [grifos no original].

Dessa maneira, o capitalismo industrial contribuiu para o desenvolvimento da associação de trabalhadores, na condição de direito social, buscando melhores condições de vida, trabalho e salário, consoante também evidenciou José Martins Catharino ${ }^{8}$ :

[...] o tríplice individualismo (político-econômico-anti-social), ingrediente da Primeira Revolução Industrial, também concorreu para o nascimento e progressão do Direito Sindical. A este propiciou, como reação jurídica em favor de uma liberdade real, capaz de operar em favor de uma igualdade também mais real, a que resulta do tratamento desigual de sujeitos desiguais. No caso, através do

\footnotetext{
${ }^{6}$ Para maiores detalhes, consulte: MARTINS, Juliane Caravieri. Trabalho digno e direitos humanos em tempos de globalização: perspectivas para a América Latina. Belo Horizonte: Arraes Editores, 2017, p. 06-56.

${ }^{7}$ SUSSEKIND, Arnaldo. Direito internacional do trabalho. 3 ed. atual. São Paulo: LTr, 2000, p. 84-85.

${ }^{8}$ CATHARINO, José Martins. Tratado elementar de direito sindical: doutrina, legislação. São Paulo: LTr, 1977, p. 22.
} 
Revista Jurídica Trabalho e Desenvolvimento Humano Procuradoria Regional do Trabalho da 15a Região

reconhecimento do direito de associação - ontologicamente anti-individualista em benefício dos econômica e individualmente mais fracos do que seus oponentes capitalistas, detentores dos meios de produção.

Nesse sentido, de espontaneidade sócio-histórica, o Direito Sindical é mais Direito do Trabalho do que o "Direito Individual do Trabalho". Mais Direito, porque mais social, fundado em solidariedade específica, e não em egoísmo generalizado, apesar das restrições que possa acarretar à liberdade de trabalho, individualmente considerada. [grifos no original]

Portanto, o direito de associação dos trabalhadores se fortaleceu ao longo do século XX, sobretudo a partir de 1919, com a institucionalização do Direito do Trabalho ${ }^{9}$, a constitucionalização dos direitos sociais ${ }^{10}$, bem como a internacionalização dos direitos humanos após o término da Segunda Guerra Mundial. Representada pelos sindicatos ${ }^{11}$, a coletividade de trabalhadores possui papel fundamental na consolidação e proteção dos direitos laborais, pois o trabalho não pode ser considerado mera mercadoria e o trabalhador aviltado em sua dignidade. Assim, a liberdade de associação profissional e sindical encontra tutela em diversos documentos internacionais.

\footnotetext{
${ }^{9}$ De acordo com Alain Supiot, "essa explosão [das novas tecnologias da informação e da comunicação] se insere num processo iniciado com a Revolução Industrial. A exploração das energias fósseis e o progresso dos meios de comunicação haviam causado um primeiro divórcio entre o espaço-tempo das máquinas e o da vida humana. O Direito do Trabalho interveio então para reconstituir um espaço-tempo humanamente suportável. Tendo a iluminação a gás, depois a elétrica, emancipado o trabalho industrial dos ritmos da natureza (dia/noite; verão/inverno) e exposto os operários a um alongamento desmedido da duração do trabalho, o Direito veio limitar a jornada, depois o ano, depois a vida de trabalho. O impossível, o Direito substituiu pela proibição. Foram assim criados de alto a baixo os novos ritmos de vida que ordenam a vida do homem moderno e a organização de seu território: metrô, trabalho, sono, feriados" (SUPIOT, Alain. Homo juridicus: ensaio sobre a função antropológica do direito. Trad. Maria Ermantina de Almeida Prado Galvão. São Paulo: WMF Martins Fontes, 2007, p. 164-165).

${ }^{10}$ No início do século XX, houve o Constitucionalismo Social, que representou a inclusão de vários direitos trabalhistas e normas de proteção aos trabalhadores nos textos das Constituições, sendo precursoras a do México e a da Alemanha. A Constituição do México, de 1 o de maio de 1917, incorporou os direitos trabalhistas como: jornada máxima de oito horas, proibição do trabalho de menores de doze anos, limitação a seis horas da jornada de trabalho dos menores de dezesseis anos, descanso semanal após seis dias de trabalho, proteção à maternidade, salário mínimo, direito de greve lícita quando almejar o equilíbrio entre os fatores de produção etc. Na Alemanha, a Constituição de Weimar, aprovada em 31 de julho de 1919, também repercutiu na Europa ao elevar vários direitos dos trabalhadores ao patamar constitucional, principalmente na seara das relações coletivas de trabalho, tais como: participação dos trabalhadores na empresa, liberdade de coalizão e sindicalização etc. Para maiores detalhes, consulte SOUTO MAIOR, Jorge Luiz. Curso de direito do trabalho: teoria geral do direito do trabalho. v. 1, parte 1, São Paulo: LTr, 2011.

${ }^{11}$ Segundo Octávio Bueno Magano, o sindicato é a "associação de pessoas físicas ou jurídicas, que exerce atividade profissional ou econômica, para a defesa dos respectivos interesses" (MAGANO, Octávio Bueno. Manual de direito do trabalho. São Paulo: LTr, 1992, p. 96). Por sua vez, Mauricio Godinho Delgado dispõe que os "sindicatos são entidades associativas permanentes, que representam trabalhadores vinculados por laços profissionais e laborativos comuns, visando tratar de problemas coletivos das respectivas bases representadas, defendendo seus interesses trabalhistas e conexos, com o objetivo de lhes alcançar melhores condições de labor e vida" [grifos no original] (DELGADO, Mauricio Godinho. Curso de direito do trabalho. 16 ed. São Paulo: LTr, 2017, p. 1511).
} 
Revista Jurídica Trabalho e Desenvolvimento Humano

Procuradoria Regional do Trabalho da 15a Região

No âmbito do sistema global de proteção aos direitos humanos, tem-se a Declaração Universal dos Direitos Humanos ${ }^{12}$ que previu no art. 23 , item 4 que todo ser humano tem direito a organizar sindicatos e a neles ingressar para proteção de seus interesses. O Pacto Internacional dos Direitos Econômicos, Sociais e Culturais (PIDESC) ${ }^{13}$ que estabeleceu no art. 8o diversos preceitos sobre a associação, destacando-se no parágrafo primeiro, item 1, o direito de toda pessoa de fundar sindicatos e de se filiar ao sindicato de sua escolha, sujeitando-se unicamente aos estatutos da organização interessada, com o objetivo de promover e de proteger seus interesses econômicos e sociais ${ }^{14}$.

No sistema da Organização Internacional do Trabalho (OIT $)^{15}$ destaca-se a Declaração relativa aos Princípios e Direitos Fundamentais no Trabalho, aprovada em 1998, ao estabelecer quatro áreas prioritárias para a concretização dos direitos humanos trabalhistas, a saber: liberdade sindical e reconhecimento efetivo do direito de negociação coletiva; eliminação de todas as formas de trabalho forçado ou obrigatório; abolição efetiva do trabalho infantil e eliminação da discriminação em matéria de emprego e ocupação. A OIT valoriza, desde sua fundação, o direito à livre associação sindical e a negociação coletiva em diversos instrumentos normativos, em especial na Convenção ${ }^{\circ} 87$ sobre a Liberdade Sindical e Proteção ao Direito de Sindicalização (1948) e na Convenção $n^{\circ} 98$ sobre Direito de Sindicalização e de Negociação Coletiva $(1949)^{16}$, consideradas "Convenções Fundamentais"17.

\footnotetext{
${ }^{12}$ Foi aprovada pela Resolução no 217 A (III) da Assembleia Geral das Nações Unidas (ONU) em 10 de dezembro de 1948. ${ }^{13}$ Foi adotado pela Resolução no 2.200-A (XXI) da Assembleia Geral da ONU, em 16 de dezembro de 1966. No Brasil, foi aprovado pelo Decreto Legislativo no 226, de 12 de dezembro de 1991; ratificado em 24 de janeiro de 1992 e promulgado pelo Decreto $\mathrm{n}$ - 591, de 06 de julho de 1992.

14 UNIVERSIDADE DE SÃO PAULO (USP). Biblioteca virtual de direitos humanos. Disponível em: http://www.direitoshumanos.usp.br/. Acesso em: 07 jul. 2020.

${ }^{15}$ O sistema da OIT é compreendido como sistema global "especial" de proteção aos direitos humanos porque possui regras e princípios que tutelam em específico o labor e os direitos humanos dele decorrentes. O conjunto de normas deste sistema (declarações, recomendações e convenções) atua no aperfeiçoamento e na adequação das relações entre trabalho e capital.

${ }^{16} \mathrm{Em}$ razão dos limites metodológicos deste ensaio, não será possível analisar mais detidamente as convenções da OIT e demais instrumentos normativos, assim, consulte MARTINS, Juliane Caravieri. Trabalho digno e direitos humanos em tempos de globalização: perspectivas para a América Latina. Belo Horizonte: Arraes Editores, 2017.

17 ORGANIZAÇÃO INTERNACIONAL DO TRABALHO (OIT). Ratificaciones por convenio. Disponível em https://www.ilo.org/dyn/normlex/es/f?p=NORMLEXPUB:12001:0::NO. Acesso em: 26 mar. 2020.
} 
Revista Jurídica Trabalho e Desenvolvimento Humano

Procuradoria Regional do Trabalho da 15a Região

No sistema regional interamericano de proteção aos direitos humanos se evidencia a pioneira Declaração Americana dos Direitos e Deveres do Homem ${ }^{18}$, que antecedeu em oito meses a Declaração Universal, disciplinando no art. 22, alínea "d" que toda pessoa tem o direito de se associar com outras a fim de promover, exercer e proteger os seus interesses legítimos, de ordem política, econômica, religiosa, social, cultural, profissional, sindical ou de qualquer outra natureza. Por sua vez, o Protocolo de San Salvador ${ }^{19}$, ao tratar especificamente de direitos sociais, econômicos e culturais, estabeleceu no art. 8o os direitos sindicais, permitindo, em síntese, aos trabalhadores se organizar sindicatos e filiar-se ao de sua escolha, para proteger e promover seus interesses, inclusive formar organizações sindicais internacionais e associar-se à de sua escolha ( $\$ 1$ ㅇánea "a")20 .

Ademais, a OEA também aprovou a Carta Democrática Interamericana, em 11 de setembro de 2001, que estabeleceu diretrizes para a democracia representativa, evidenciando, em seu Preâmbulo, o "direito dos trabalhadores de se associarem livremente para a defesa e promoção de seus interesses é fundamental para a plena realização dos ideais democráticos". Ela também destacou art. 10 que a promoção e o fortalecimento da democracia requerem o exercício pleno e eficaz dos direitos dos trabalhadores e a aplicação de normas trabalhistas básicas consagradas pela OIT, pois a democracia se fortalece com a melhoria das condições de trabalho e da qualidade de vida dos trabalhadores do Hemisfério ${ }^{21}$.

Por fim, no âmbito do regionalismo latino-americano, destaca-se o MERCOSUL (Mercado Comum do Sul), criado em 1991, e suas normas de integração regional, em específico a Declaração Sociolaboral de 2015, aprovada na XXXIV Reunião da Comissão Sociolaboral do MERCOSUL, ocorrida em Montevidéu, entre 13 e 15 de maio de 2013 - que, em certa medida, revisou a Declaração de 1998. O Capítulo III tratou de Direitos Coletivos e inicia-se com o art. 16ㅇ prevendo que "todos os

\footnotetext{
${ }^{18}$ Foi aprovada em abril de 1948 pela Resolução XXX da Ata Final da IX Conferência Internacional Americana ocorrida em Bogotá.

${ }^{19}$ Foi adotado pela Assembleia Geral da Organização dos Estados Americanos (OEA), em São Salvador - El Salvador, em 17 de novembro de 1988, entrou em vigor no plano internacional em 16 de novembro de 1999. Ele é conhecido como o Protocolo Adicional à Convenção Americana sobre Direitos Humanos em Matéria de Direitos Econômicos, Sociais e Culturais, sendo ratificado pelo Brasil em 08 de agosto de 1996.

20 UNIVERSIDADE DE SÃO PAULO (USP). Biblioteca virtual de direitos humanos. Disponível em: http://www.direitoshumanos.usp.br/. Acesso em: 07 jul. 2020.

21 ORGANIZAÇÃO DOS ESTADOS AMERICANOS (OEA). Carta democrática interamericana. Disponível em: http://www.oas.org/OASpage/port/Documents/Democractic Charter.htm. Acesso em: 07 jul. 2020.
} 
Revista Jurídica Trabalho e Desenvolvimento Humano

Procuradoria Regional do Trabalho da 15a Região

empregadores e trabalhadores têm o direito de constituir as organizações que considerem convenientes, assim como de se afiliar a estas organizações, em conformidade com as legislações nacionais vigentes" (item 1). Os Estados-Partes deverão garantir aos trabalhadores a "liberdade de filiação, de não filiação e desfiliação, sem que isto comprometa o ingresso em um emprego, a continuidade ou a oportunidade de ascensão no mesmo" (item 4, alínea "a")22.

Além do plano internacional, o direito de associação sindical também encontra assento na Constituição Federal do Brasil de 1988 que - ancorada nos princípios da dignidade humana e da cidadania - trouxe extenso catálogo de direitos fundamentais arrolados no Título II - Dos Direitos e Garantias Fundamentais ${ }^{23}$, dentre outros dispersos ao longo do texto constitucional, incluindo não somente os direitos civis e políticos (primeira dimensão), mas também os direitos sociais, econômicos e culturais (segunda dimensão).

A Constituição reconheceu a essencialidade do trabalho como instrumento de afirmação da dignidade do trabalhador, seja em sua individualidade como ser humano, seja em seu contexto familiar e social. Há um conjunto mínimo de direitos trabalhistas individuais (art. $7^{\circ}, C F$ ) e coletivos (art. 8o a 11, CF), incluindo a livre associação lícita em termos gerais (art. 5ํ, XVII, CF) e a associação profissional e sindical (art. 8ㅇ) que se enquadram na categoria de direitos fundamentais do cidadão trabalhador. Cabe frisar que nem todos os direitos sociais fundamentais necessitam de prestações estatais, havendo aqueles de defesa, de cunho negativo, os quais impõem condutas omissivas por parte do seu destinatário (Estado ou particular). Logo, tais direitos assumem a característica de

\footnotetext{
22 ITAMARATY. Declaração Sociolaboral do MERCOSUL de 2015. Disponível em: http://www.itamaraty.gov.br/ptBR/notas-a-imprensa/10519-declaracao-sociolaboral-do-mercosul-de-2015-i-reuniao-negociadora-brasilia-17-dejulho-de-2015. Acesso em: 20 mai. 2020.

${ }^{23}$ Segundo Luigi Ferrajoli, “[...] são 'direitos fundamentais' todos aqueles direitos subjetivos que dizem respeito universalmente a 'todos' os seres humanos enquanto dotados do status de pessoa, ou de cidadão ou de pessoa capaz de agir. Compreendendo por 'direito subjetivo' qualquer expectativa positiva (a prestação) ou negativa (a não lesão) vinculada a um sujeito por uma norma jurídica, e por status a condição de um sujeito prevista também esta por uma norma jurídica positiva qual pressuposto da sua idoneidade a ser titular de situações jurídicas e/ou autor dos atos que estão em exercício" (FERRAJOLI, Luigi. Por uma teoria dos direitos e dos bens fundamentais. Trad. Alexandre Salim, Alfredo Copetti Neto, Daniela Cadermatori, Hermes Zaneti Júnior, Sérgio Cadermatori. Porto Alegre: Livraria do Advogado, 2011, p. 09).
} 
"liberdades sociais" com status negativus socialis ou status socialis libertatis ${ }^{24}$, como é o caso do direito de livre associação profissional e sindical.

Nesse sentido, o art. 511, caput da Consolidação das Leis do Trabalho (CLT) determinou que fosse lícita a associação para fins de estudo, de defesa e de coordenação dos interesses econômicos ou profissionais de todos os que, como empregadores, empregados, agentes ou trabalhadores autônomos, ou profissionais liberais, exercessem, respectivamente, a mesma atividade ou profissão ou atividades ou profissões similares ou conexas. Assim, como prerrogativas dos Sindicatos, vislumbra-se a representação da categoria; a celebração de acordos e convenções coletivas de trabalho; a colaboração técnica com o Estado; a designação de representantes e a imposição de contribuições a todos que participem das categorias econômicas ou profissionais (art. $513, \mathrm{CLT})$.

Entretanto, a partir de 2014, as turbulências no cenário político brasileiro culminaram com a chegada ao poder, em 2016, do Presidente Michel Temer, cujo governo (2016-2018) aprovou a Lei no 13.467/2017, chamada de "Reforma Trabalhista", que alterou vários artigos da CLT, da Lei no 6.019/1974, da Lei n 8.036/90 e da Lei no 8.212/1991 sob o discurso de que as normas trabalhistas estavam obsoletas e precisavam ser modernizadas às novas relações de trabalho impostas pelo sistema capitalista ${ }^{25}$, alterando profundamente o sistema juslaboral de proteção aos trabalhadores.

O governo de Temer viabilizou a vitória da direita conservadora ao eleger Jair Bolsonaro para a Presidência da República (2019-2022), que se propõe a atender os anseios do capital global mediante a adoção de políticas e ações neoliberais e restritivas aos direitos sociais como, por exemplo, os cortes orçamentários nas verbas da educação pública.

Esse desmonte dos direitos laborais - ocorrido nas últimas décadas sob a influência do Consenso de Washington - agora se agrava pelo fortalecimento de governos latino-americanos mais alinhados com a globalização neoliberal. Os governos de "esquerda" se perderam numa série de escândalos de corrupção, possibilitando “[...] la elección de Maurício Macri en Argentina, los golpes

\footnotetext{
${ }^{24}$ SARLET, Ingo Wolfgang. Os direitos fundamentais sociais na Constituição de 1988. Revista Diálogo Jurídico, a. I, v. I, n. 1, Salvador, abril de 2001, p. 19.

${ }^{25}$ MARTINS, Juliane Caravieri. Trabalho digno e direitos humanos em tempos de globalização: perspectivas para a América Latina. Belo Horizonte: Arraes Editores, 2017, p. 06-56.
} 
de Estado en Paraguay y en Brasil, y la elección de Donald Trump en los Estados Unidos, para citar solamente algunos ejemplos [...]"26, havendo o 'giro' à direita conservadora.

Nesse contexto de 'giro' à direita, a reforma trabalhista apregoou a adoção da intervenção mínima do Poder Judiciário nas negociações trabalhistas (art. 8ำ, §3ำ, CLT) mediante a valorização das normas autônomas, mas isso não foi vislumbrado em diversos dispositivos alterados no texto consolidado, contrariando, inclusive, preceitos internacionais e diretrizes da Constituição de 1988.

No campo do Direito Coletivo do Trabalho, houve o enfraquecimento dos sindicatos ao se excluir de imediato a cobrança da contribuição sindical obrigatória, tornando-a facultativa, sem outra contrapartida financeira e sem um período de transição ou adaptação dos sindicatos a essa "nova" situação (art. 579, CLT), sufocando financeiramente as entidades sindicais. Nesse cenário, dificilmente um sindicato financeiramente enfraquecido terá condições de livremente pactuar nas negociações coletivas em prol dos trabalhadores.

A "Reforma Trabalhista" de 2017 permitiu a realização de banco de horas, prorrogação e compensação de jornada (art. 59, CLT) e jornada de trabalho 12×36 (art. 59-A, CLT) por acordo individual, esvaziando, mais uma vez, a atuação sindical. Houve, ainda, a criação da figura do empregado "hipersuficiente" (art. 444, parágrafo único, CLT), que poderá sozinho, sem participação do sindicato, negociar diretamente com o empregador todos os direitos previstos no art. 611-A da CLT, em afronta aos princípios trabalhistas cristalizados nos arts. 2ำ e 3ำ da CLT (a subordinação do empregado ao poder de direção do empregador; a não eventualidade ou habitualidade na prestação dos serviços; a onerosidade ou remuneração e a pessoalidade na prestação dos serviços).

Ao afastarem o sindicato da negociação sobre esses direitos, tais normas violam também o princípio da equivalência dos contratantes coletivos que reconhece um "estatuto sociojurídico semelhante a ambos os contratantes coletivos (o obreiro e o empresarial)"27 porque o trabalhador isoladamente não possui nenhum instrumento eficaz de pressão para a concretude da negociação em prol do trabalho digno.

\footnotetext{
${ }^{26}$ DUDIUK, Pedro e PRADO, Silvio. Introdução. In: AMARAL, Fernanda Pattaro [et. al.]. (Comp.). El desangramiento latinoamericano: un panorama político contemporáneo sobre la reorganización y la reconfiguración del estado neoliberal. Barranquilla: Corporación Universitaria Americana, 2018, p. 14.

${ }^{27}$ DELGADO, Mauricio Godinho. Curso de direito do trabalho. 16. ed. São Paulo: LTr, 2017, p. 1489.
} 
Conjuntamente, houve a extinção da homologação sindical nas rescisões contratuais de empregados com mais de um ano de vigência de contrato de trabalho ante a revogação do §1으 do art. 477, CLT. Por fim, foi dispensada a autorização prévia do sindicato para a ocorrência de dispensas imotivadas individuais, plúrimas ou coletivas (art. 477-A, CLT) que geram profundos impactos sociais e laborais nos empregos de determinada região, havendo reflexos que vão além dos contratos de emprego rescindidos em massa.

Logo, é perceptível que não houve a valorização do papel dos sindicatos com a Reforma e, por via reflexa, está se sufocando o direito de livre associação sindical, pois os trabalhadores não irão se associar a sindicatos que não possam efetivamente negociar direitos em favor da categoria obreira.

Esse processo de sufocamento dos sindicatos poderá se agravar com o avanço tecnológico, inclusive com a adoção de plataformas digitais na contratação de trabalhadores, como é o caso dos entregadores de bens e alimentos que prestam serviços a aplicativos, pois haveria uma pulverização na representação sindical dessa categoria.

Tais situações se mostram agravadas pelo uso intensivo e desvirtuado da tecnologia no mundo do trabalho possibilitando jornadas extenuantes e contínuas que ultrapassam a delimitação entre o local de trabalho e o local de moradia/descanso e vice-versa, como no caso dos trabalhadores a serviço dos aplicativos, sob o influxo de (talvez) nova etapa do sistema capitalista, agora denominada de capitalismo de plataforma ${ }^{28}$ que poderá potencializar as dificuldades da atuação sindical e da livre associação de trabalhadores.

Portanto, a participação dos sindicatos é primordial nas relações de trabalho para a efetivação do Estado Democrático Social e de Direito, não podendo as ordens econômica e social nos países capitalistas estarem ao livre alvedrio do laissez-faire e ao exclusivo controle dos entes privados. Faz-se imperiosa a manutenção de um diálogo social entre trabalhadores, empregadores, sociedade e Estado a fim de garantir a democracia. Nesse sentido, a livre associação sindical é direito

\footnotetext{
${ }^{28}$ Para maiores detalhes, consulte: KALIL, Renan Bernardi. Capitalismo de plataforma e direito do trabalho: crowdwork e trabalho sob demanda por meio de aplicativos. Tese de Doutorado. Universidade de São Paulo (USP), Programa de Pós-Graduação em Direito, 2019. 366 f.
} 
humano e fundamental e a participação sindical nas negociações coletivas se mostra fundamental para a efetividade dos direitos laborais e para a busca da concretização do trabalho digno.

\section{Pandemia de COVID-19, instrumentos legislativos e reflexos no mundo do trabalho}

$\mathrm{Na}$ atualidade, a difusão da pandemia internacional de coronavírus e de infecções por COVID-19 no Brasil gerou desafios sociais, econômicos e administrativos, que oportunizaram a edição de diferentes instrumentos legislativos - leis, medidas provisórias, decretos, resoluções e portarias - na tentativa de oferecer possíveis soluções e moldar uma "legislação emergencial".

A partir da publicação da Portaria no 188, de 03 de fevereiro de 2020, que promoveu o reconhecimento formal da emergência em saúde pública pelo vírus no país, outros instrumentos com medidas para enfrentamento da situação foram editados. O primeiro deles foi a Lei no 13.979 , de 6 de fevereiro de 2020, que dispôs sobre medidas gerais para enfrentamento da emergência de saúde pública e elencou, dentre outras, as medidas de isolamento e quarentena, no art. 3‥

Para garantir o cumprimento de tais medidas de distanciamento social, o art. 3응 estabeleceu que "será considerado falta justificada ao serviço público ou à atividade laboral privada o período de ausência decorrente das medidas previstas neste artigo" (§ 3으), ou seja, sem prejuízo à remuneração do empregado; "as pessoas deverão sujeitar-se ao cumprimento das medidas previstas neste artigo, e o descumprimento delas acarretará responsabilização, nos termos previstos em lei" (§ 4ㅇ); e "as medidas previstas neste artigo, quando adotadas, deverão resguardar o exercício e o funcionamento de serviços públicos e atividades essenciais" (§ 8ㅇ).

Assim, apesar de a Lei no 13.979/2020 mencionar os serviços públicos e as atividades essenciais, a definição do rol de tais atividades apenas ocorreu posteriormente com a publicação do Decreto nํ 10.282, de 20 de março de 2020. Esse Decreto, editado no âmbito federal, prevê, dentre os serviços públicos e as atividades essenciais (art. 3ํ), a "produção, distribuição, comercialização e entrega, realizadas presencialmente ou por meio do comércio eletrônico, de produtos de saúde, higiene, limpeza, alimentos, bebidas e materiais de construção" (inciso XII) e os "serviços de transporte, armazenamento, entrega e logística de cargas em geral" (inciso XXII). 
Nesse Decreto, os serviços de entrega foram reconhecidos como atividades essenciais nos incisos XII e XXII do art. 3ำ, a fim de reduzir a movimentação e a aglomeração de indivíduos nos estabelecimentos comerciais, possibilitando aos consumidores que permaneçam em suas residências a partir do deslocamento dos entregadores para efetuar as entregas de produtos de saúde, higiene e alimentos, por exemplo.

Ressalte-se que o Decreto no $10.282 / 2020$ se dirige ao âmbito federal, de sorte que os Estados puderam, em acréscimo, editar decretos para contemplar diferentes atividades essenciais. A exemplo, no Estado de São Paulo, o Decreto no 64.881, de 22 de março de 2020, com a decretação da medida de quarentena, o art. 20 suspendeu "o consumo local em bares, restaurantes, padarias e supermercados, sem prejuízo dos serviços de entrega ('delivery') e 'drive thru'” (inciso II).

Nesse Decreto, a suspensão não se aplica aos estabelecimentos que tenham por objeto atividades essenciais como, dentre outros, "supermercados e congêneres, bem como os serviços de entrega ('delivery') e 'drive thru' de bares, restaurantes e padarias". Assim, os serviços de entrega foram reconhecidos como essenciais, para garantir a manutenção das atividades econômicas, dos postos de trabalho e a garantia do suprimento das necessidades de consumidores.

Em acréscimo, diversas Medidas Provisórias (MP) foram editadas e impactaram o cenário juslaboral durante a pandemia de COVID-19, a saber a MP 927, a MP 928, a MP 936, a MP 944, a MP 945 e a MP 946. Dentre tais Medidas, a MP 927 e a MP 936 se destacaram sobremaneira pelas medidas que estabelecem.

A MP 927 estabeleceu medidas trabalhistas a serem adotadas pelos empregadores, com vistas à preservação do emprego e da renda durante o estado de calamidade pública reconhecido nacionalmente causado pelo espraiamento de COVID-19. Dentre as medidas possíveis, a MP contemplou, no art. 3ำ, o teletrabalho, a antecipação de férias individuais, a concessão de férias coletivas, o aproveitamento e a antecipação de feriados, o banco de horas, a suspensão de exigências administrativas em segurança e saúde no trabalho, o direcionamento do trabalhador para qualificação ${ }^{29}$ e o diferimento do recolhimento do Fundo de Garantia do Tempo de Serviço (FGTS).

\footnotetext{
${ }^{29}$ A medida trabalhista de "direcionamento do trabalhador para qualificação" (art. 18) prevista na MP 927/2020 foi revogada pelo art. 2ㅇ da MP 928/2020.
} 
Nessa MP, as medidas se propunham a possibilitar que o empregado pudesse exercer a atividade laborativa na sua própria residência pelo teletrabalho, bem como que o empregado não exercesse a atividade, a partir de manejos relacionados à antecipação de férias individuais, à concessão de férias coletivas e à antecipação de feriados. Essas medidas trabalhistas (arts. 4ํㅜ, 6으, 11 e 13) não necessitavam, para serem adotadas, de negociação coletiva (acordo e/ou convenção coletiva), dispensando, por conseguinte, a atuação do sindicato da categoria. Em 19 de julho de 2020, a MP 927 caducou, de sorte que não seus dispositivos não poderão ser utilizados como alternativas ao cenário pandêmico.

Já a MP 936 instituiu o Programa Emergencial de Manutenção do Emprego e da Renda, com os objetivos (art. 2º) de "preservar o emprego e a renda" (inciso I), "garantir a continuidade das atividades laborais e empresariais" (inciso II) e "reduzir o impacto social decorrente das consequências do estado de calamidade pública e de emergência de saúde pública" (inciso III). Para tanto, dispôs sobre medidas trabalhistas complementares (art. 3ำ), que dão forma ao Programa Emergencial, a saber "o pagamento de Benefício Emergencial de Preservação do Emprego e da Renda" (BEm) (inciso I), "a redução proporcional de jornada de trabalho e de salários" (inciso II) e “a suspensão temporária do contrato de trabalho" (inciso III).

O BEm foi criado para ser pago mensalmente, com recursos União e com gerenciamento do Ministério da Economia, durante a redução proporcional de jornada de trabalho e de salários e/ou a suspensão temporária do contrato de trabalho.

Segundo o art. 7ำ, a redução proporcional de jornada de trabalho e de salários pode ser de até noventa dias e possui, como requisitos, a "preservação do valor do salário-hora de trabalho" (inciso I), a "pactuação por acordo individual escrito entre empregador e empregado, que será encaminhado ao empregado com antecedência de, no mínimo, dois dias corridos" (inciso II) e a “redução da jornada de trabalho e de salário, exclusivamente, nos seguintes percentuais: a) vinte e cinco por cento; b) cinquenta por cento; ou c) setenta por cento" (inciso III). Salienta-se que a 
previsão da pactuação por acordo individual foi objeto de Ação Direta de Inconstitucionalidade (ADI 6363) junto ao Supremo Tribunal Federal (STF) ${ }^{30}$.

A MP prevê que o percentual de redução de $25 \%, 50 \%$ e $70 \%$ servirão para cálculo do BEm, que se valerá do seguro-desemprego como base. Para tanto, a MP previu que no caso de redução proporcional de $25 \%$, todos os empregados poderão se valer de negociação coletiva ou acordo individual; no caso de redução proporcional de $50 \%$, todos os empregados poderão se valer de negociação coletiva e apenas os empregados com salário igual ou inferior a $\mathrm{R} \$ 3.135,00$ ou empregados com diploma de nível superior com salário igual ou superior a dois tetos do RGPS ( $R \$ 12.202,12)$ poderão se valer do acordo individual; e no caso de redução proporcional de $70 \%$, todos os empregados poderão se valer de negociação coletiva e apenas os empregados com salário igual ou inferior a $\mathrm{R} \$ 3.135,00$ ou empregados com diploma de nível superior com salário igual ou superior a dois tetos do RGPS $(\mathrm{R} \$ 12.202,12)$ poderão se valer do acordo individual. Ressalte-se que outros percentuais poderão ser fixados mediante negociação coletiva.

Já a suspensão temporária do contrato de trabalho pode ser de até sessenta dias, podendo ser fracionada em até dois períodos de trinta dias. O valor do BEm será calculado com base no seguro-desemprego e variará conforme a receita bruta da empresa no ano de 2019 e a ajuda compensatória mensal devida pelo empregador.

No caso de empresas com receita bruta inferior a $\mathrm{R} \$ 4.800 .000,00$, o valor será de $100 \%$ o valor do seguro-desemprego, sem obrigatoriedade de ajuda compensatória mensal devida pelo empregador; já nas empresas com receita bruta superior a $\mathrm{R} \$ 4.800 .000,00$, o valor será de $70 \%$ o valor do seguro desemprego, com a obrigatoriedade de ajuda compensatória mensal devida pelo empregador no importe de $30 \%$ do valor do salário do empregado.

Salienta-se que, em ambas as modalidades, a suspensão poderá ser acordada por negociação coletiva, de sorte que o acordo individual poderá ser usado apenas pelos empregados com salário igual ou inferior a $\mathrm{R} \$ 3.135,00$ ou empregados com diploma de nível superior com salário igual ou superior a dois tetos do RGPS (R\$12.202,12) poderão se valer do acordo individual.

\footnotetext{
30 Para maiores detalhes, consulte: DELGADO, Gabriela Neves; AMORIM, Helder Santos. A legislação pandêmica e o perigoso regime de exceção aos direitos fundamentais trabalhistas. Revista Jurídica Trabalho e Desenvolvimento Humano, v. 3, 29 set. 2020.
} 
Mediante aprovação do Congresso Nacional, a MP 936 foi convertida na Lei no 14.020, de 06 de julho de 2020.

Nota-se que, como denominador comum, tanto a MP 927 quanto a MP 936 possibilitam alterações substanciais no contrato de trabalho e na modalidade de exercício da atividade laborativa por acordo individual, preterindo a negociação coletiva e a importância da entidade sindical na garantia de direitos juslaborais.

Além das MPs, o cenário pandêmico oportunizou a publicação da Lei no 13.982, de 02 de abril de 2020. Essa Lei impactou as searas do Direito da Seguridade Social, por estabelecer parâmetros adicionais para fins de elegibilidade ao Benefício de Prestação Continuada popularmente conhecido como BPC e Benefício Assistencial - da Lei no 8.742/1993 (Lei Orgânica da Assistência Social/LOAS), e do Direito do Trabalho, pela previsão de auxílio-emergencial aos trabalhadores.

Tal auxílio - comumente conhecido como "Coronavoucher" - está disposto no art. 2o e será pago aos trabalhadores durante três meses, no importe de $\mathrm{R} \$ 600,00$ (seiscentos reais). Para fazer jus ao auxílio-emergencial, o trabalhador precisa ser maior de dezoito (18) anos de idade, com exceção às mães adolescentes (inciso I); não possuir emprego formal ativo (inciso II); não ser titular de benefício previdenciário, benefício assistencial, seguro-desemprego ou programa de transferência de renda federal (com exceção dos $\$ 1$ 으 e $§ 2^{\circ}$ do art. 2ํ) (inciso III); com renda familiar mensal per capita de até meio salário-mínimo ou renda familiar mensal total de até três salários mínimos (inciso IV); que, no ano de 2018, não tenha recebido rendimentos tributáveis acima de $\mathrm{R} \$$ 28.559,70 (inciso V); e que exerça atividade na condição de microempreendedor individual (MEI), de contribuinte individual do Regime Geral de Previdência Social (art. 21, §2º, caput e inciso da Lei no 8.212/1991) ou de trabalhador informal, seja empregado, autônomo ou desempregado, de qualquer natureza, inclusive o intermitente inativo (inciso VI, "a", "b" e "c"). 
3. A atuação do sindicato na promoção de direitos dos entregadores de aplicativos em tempos de coronavírus

A estrutura sindical brasileira é caracterizada por ser, de acordo com Sidarta Sória e Silva ${ }^{31}$, "fragmentada e dispersa por muitos sindicatos municipais, em sua maioria pouco expressivos e de influência restrita a pequenas áreas", o que reflete na redução da capacidade do poder de barganha.

Em 2017, a Reforma Trabalhista estabeleceu, conjuntamente com outras medidas, a retirada da obrigatoriedade da contribuição sindical e a adoção de requisitos mais burocráticos para o recolhimento das contribuições sindicais, contribuindo para o enfraquecimento da atuação dos sindicatos no cenário político, social e econômico brasileiro.

Assim, a despeito de as recentes inovações legislativas que demonstraram um viés político, sem a existência de uma atuação democrática e participativa da classe trabalhadora, a autonomia sindical revela-se elemento indispensável à garantia dos direitos coletivos do trabalho.

O diálogo com a classe trabalhadora mostra-se necessário, por meio de um processo participativo e, por conseguinte, democrático na estrutura sindical, com medidas harmônicas e condizentes com os direitos trabalhistas previstos na Constituição e na legislação trabalhista.

Acerca do fortalecimento à horizontalização sindical, Maurício Godinho Delgado afirma que a transição democrática ocorre pelo "afastamento dos traços corporativistas e autoritários do velho modelo sindical; de outro lado [...], o implemento de medidas eficazes de proteção e reforço à estruturação e atuação democráticas do sindicalismo na sociedade brasileira" 32 .

Nesse sentido, afigura-se necessária a participação e discussão política da classe trabalhadora, propiciando a democratização do movimento sindical a partir de uma estrutura horizontal e participativa. No que concerne à participação da categoria, na atualidade, destacam-se as mobilizações realizadas por entregadores ${ }^{33}$, que, sem vínculo de emprego, estão atrelados às empresas-aplicativo.

31 SILVA, Sidartha Sória e. Reestruturação produtiva, crise econômica e os rumos do sindicalismo no Brasil. Brasília: Faculdade Milton Campos, Conselho de Reitores das Universidades Brasileiras, 2001, p. 75.

32 DELGADO, Mauricio Godinho. Curso de direito do trabalho. 16. ed. rev. e ampl. São Paulo: LTr, 2017, p. 1369.

${ }^{33}$ Para maiores detalhes sobre as condições de trabalho dos entregadores durante a pandemia de COVID-19, consulte: ABÍLIO, Ludmila Costhek; ALMEIDA, Paula Freitas de; AMORIM, Henrique; CARDOSO, Ana Cláudia Moreira; FONSECA, 
Tais movimentos de paralisação, organizados nos dias 01 de julho de 2020 e 25 de julho de 2020 e popularmente denominados como "Breque dos Apps", tinham como uma de suas principais pautas a garantia de direitos dos entregadores vinculados às empresas-aplicativo, os quais, durante a pandemia no Brasil, tiveram aumento expressivo na demanda de entregas e, em contrapartida, a precarização de suas atividades.

Neste aspecto, é imperioso destacar que o aumento da carga horária de trabalho não foi acompanhado do proporcional incremento da remuneração. Isso porque, de acordo com Relatório Técnico realizado pela Rede de Estudos e Monitoramento Interdisciplinar da Reforma Trabalhista REMIR $^{34}$, constatou-se que, em que pese tenha ocorrido o aumento do percentual - de $50 \%$ para $73 \%$ - de entregadores que recebiam até $\mathrm{R} \$ 560,00$ semanais, dentre os entrevistados, "houve aumento em $100 \%$ dos que auferem menos do que $\mathrm{R} \$ 260$ por semana e, por outro lado, redução para em torno de $25 \%$ os que auferem rendimento maior que $\mathrm{R} \$ 520,00$ semanais". Então, é possível concluir que no contexto da pandemia, as empresas-aplicativo buscam a redução do valor da hora de trabalho dos entregadores.

Diante disso, como garantias pleiteadas pelos entregadores no "Breque dos Apps", estão o aumento do valor da taxa mínima paga pelas entregas realizadas, a melhoria nas condições de saúde e a concessão de auxílios, como alimentação e transporte. Conjuntamente, os entregadores reivindicaram o fim dos bloqueios de entregadores pelos aplicativos ou, alternativamente, a criação de um canal de defesa, com o intuito de que os entregadores pudessem apresentar sua versão.

Em relação às condições mínimas exigidas para um meio ambiente de trabalho seguro e sadio, os entregadores pleitearam o pagamento de seguro contra roubo e furto, de acidente e de vida, bem como um local para descanso e alimentação. No que tange às jornadas, requereram o fim das pontuações do aplicativo, já que a presença de um ranking leva os trabalhadores ao cumprimento de jornadas extenuantes para conseguir maiores remunerações, perdendo sua autonomia.

\footnotetext{
Vanessa Patriota da; KALIL, Renan Bernardi; MACHADO, Sidnei. Condições de trabalho de entregadores via plataforma digital durante a COVID-19. Revista Jurídica Trabalho e Desenvolvimento Humano, v. 3, 8 jun. 2020.

34 ABÍLIO, Ludmila Costhek; ALMEIDA, Paula Freitas de; AMORIM, Henrique; CARDOSO, Ana Cláudia Moreira; FONSECA, Vanessa Patriota da; KALIL, Renan Bernardi; MACHADO, Sidnei. Condições de trabalho em empresas de plataforma digital: os entregadores por aplicativo durante a Covid-19. São Paulo: REMIR, 2020. p. 3.
} 
Os "Breques dos Apps" foram organizados por entregadores da capital paulista (São Paulo/SP), de maneira que a maior adesão se deu por aqueles que não tinham tido, até então, nenhuma participação ativa no movimento sindical. Em outras palavras, os "Breques" inovaram como um movimento grevista amparado nas redes sociais (tais como o instagram, facebook, twitter) e revelaram latente a participação popular, que, chamada a participar, buscou evitar a realização de pedidos nos aplicativos de entregas nos dias das paralisações.

Em entrevista concedida à Digilabour, em 02 de julho de 2020, Paulo Lima, popularmente conhecido como "Galo", uma das principais figuras do movimento denominado "Entregadores Antifascistas", discorreu o seguinte:

A minha ideia, dos Entregadores Antifascistas, é que o movimento dos entregadores seja de empoderamento do trabalhador. $O$ anarquista quer empoderar o trabalhador? O comunista quer empoderar o trabalhador? O partido político quer empoderar o trabalhador? O sindicato quer empoderar o trabalhador? O movimento social quer empoderar o trabalhador? Vamos parar de gracinha, de picuinha, e empoderar o trabalhador. As coisas não acontecem lá na frente. As coisas são agora. O trabalhador precisa de ajuda agora. [...] Eu vou falar do desafio e da luta. O maior desafio dos Entregadores Antifascistas nesse momento é conseguir se organizar sem estabelecer uma hierarquia. Conseguir se organizar para ser um movimento horizontal, mas que isso não seja algo que nos enfraqueça em relação aos inimigos que temos que enfrentar pela frente. Os inimigos ficam tentando entender nossa estrutura para nos derrubar. A gente quer fazer de uma forma que não tenha essa coisa de líder, pessoas acima. 0 poder tem que estar na mão do povo mesmo, na mão dos trabalhadores, não tem que ter líder. As pessoas não são gado, que vamos levar para cá ou levar para lá. É um movimento de pensadores. O maior desafio é como a gente vai estabelecer e estruturar um movimento sem essas hierarquias e que ainda assim consiga se defender de inimigos que estarão por vir, que a gente sabe que vai ter que enfrentar ${ }^{35}$.

À vista disso, destaca-se o posicionamento de Sidartha Sória e Silva, em que "[...] por não diferenciar, pois muitas vezes não the são oferecidas condições para isso, o sindicato oficial de um movimento sindicato político autônomo, a menção deste remete àquele, o que pode induzir ao desinteresse do trabalhador pela discussão [...]"36.

35 GROHMANN, R.; ALVES, P. É luta de classes mesmo, sem conversinha: entrevista com Galo, dos Entregadores Antifascistas. Digilabour, 2020. Disponível em: https://digilabour.com.br/2020/07/02/e-luta-de-classes-mesmo-semconversinha-entrevista-com-galo-dos-entregadores-antifascistas/. Acesso em: 10. ago. 2020.

${ }^{36}$ SILVA, Sidartha Sória e. Reestruturação produtiva, crise econômica e os rumos do sindicalismo no Brasil. Brasília: Faculdade Milton Campos, Conselho de Reitores das Universidades Brasileiras, 2001, p. 77. 
A ausência de participação da classe trabalhadora nos sindicatos e, por conseguinte, o distanciamento, é pode ser vista na atualidade, conquanto de outrora, como uma mácula que acomete e inibe - conjuntamente com outras questões políticas - a reestruturação participativa e democrática de um novo sindicalismo. Visualiza-se que, na sociedade brasileira, remanesce o ideal de um sindicalismo corporativista que, hierarquizado e distante do trabalhador, remonta ao ideal "de pelego" pela pouca atuação efetiva.

Nessa perspectiva, percebe-se que a automatização das plataformas de entrega e a ausência de uma figura patronal clara têm gera a dificuldade do reconhecimento dos trabalhadores como classe trabalhadora, de sorte que os mesmos passam a se identificar como autônomos. Nesse sentido, não são abrangidos, portanto, pelas normas celetistas e são remetidos à "subordinação algorítmica" dos trabalhadores.

Em outras palavras, a substituição da figura patronal bem definida pelo poder diretivo das empresas-aplicativo, gerenciado por algoritmos, fez com que as plataformas não fossem vistas como empregadoras, de modo que entregadores se transplantem do coletivo para o individual, como se autônomos fossem. Isso porque a estrutura da plataforma, atrelada à realização da atividade laboral essencialmente solitária (no caso dos serviços de entrega), distancia os próprios entregadores, inibindo seu reconhecimento enquanto classe.

Nesse sentido, os "Breques dos Apps" não tiveram como principal pauta o reconhecimento de vínculo empregatício dos empregadores com as empresas-aplicativo e o pagamento dos direitos e verbas dele decorrentes. Tampouco houve participação ativa e massiva dos sindicatos, especificamente da categoria dos entregadores. A representação sindical, então, se mostrou dispensável na organização e efetivação do movimento de paralisação, o que corrobora com o possível esgotamento das entidades sindicais, dando azo à nova - e não tão recente - estruturação dos movimentos de trabalhadores, ora desvinculados dos sindicatos. 
Revista Jurídica Trabalho e Desenvolvimento Humano

Procuradoria Regional do Trabalho da 15a Região

Portanto, tal situação é resultado do constante processo de precarização das relações sociais do trabalho, que, de acordo com Patrícia Benetti Cravo e Sandra Cristina Zanoni Cembraneli Correia ${ }^{37}$ :

[...] não restam dúvidas quanto à árdua caminhada na conquista de direitos sociais por aqueles que não tem o sentimento de pertencimento a uma categoria profissional, eis que não se identificam com os colegas de trabalho e têm interesses distintos, os mais vulneráveis sempre subjugados pela dinâmica do lucro.

Em acréscimo, para Ricardo Antunes, "o indivíduo chega a autoalienar suas possibilidades mais próprias, vendendo, por exemplo, sua força de trabalho sob condições que lhe são impostas", processo por ele intitulado como "subjetividade de classe" 38.

Observa-se que a precarização das relações de trabalho e as más condições laborais dos entregadores, acentuadas pela difusão da pandemia internacional de coronavírus e de infecções por COVID-19 no Brasil, refletem no afastamento dos trabalhadores dos sindicatos, sobretudo em razão do fato do sentimento de falta de representatividade dos seus interesses.

Nesse sentido, é possível vislumbrar a ascensão de movimentos de trabalhadores, desvinculados dos sindicados e pulverizados, com a participação dos trabalhadores informais a partir, principalmente, da disseminação pelos meios de comunicação e pelas redes sociais. Ressaltese que não é possível dizer por ora que tais movimentos apartados substituíram a necessidade de um movimento sindical moderno, especialmente porque é imprescindível a recuperação pelos trabalhadores da identificação como integrantes de determinada classe, com direitos e garantias.

\section{CONCLUSÃO}

A pandemia mundial causada pelo coronavírus, denominado SARS-CoV-2, afetou fortemente as sociedades e os países, com reflexos econômicos, políticos e sociais, havendo

\footnotetext{
${ }^{37}$ CRAVO, Patrícia Benetti; CORREIA, Sandra Cristina Zanoni Cembraneli. Terceirização e precarização do trabalho. In: LORA, Ilse Marcelina Bernardi; SLOMP, Angélica Cândido Nogara; GARCIA, Alessandra Souza (org.). Reforma trabalhista: um necessário olhar feminino. São Paulo: Tirant lo Blanch, 2019, p. 419.

${ }^{38}$ ANTUNES, Ricardo; ALVES, Giovanni. As mutações no mundo do trabalho na era da mundialização do capital. Educação e Sociedade. Campinas, v. 25, n. 87, mai./ago. 2004, p 349.
} 
impactos locais, regionais e globais imensuráveis, de sorte a alterar profundamente as relações sociais de trabalho e, por conseguinte, o arcabouço jurídico que as circunda. Tornou-se, então, imperiosa a criação de novas normas com vistas a amenizar os impactos sociais decorrentes da grave crise de saúde pública que acomete o mundo.

O isolamento social, por consequência, prejudicou severamente aqueles que, em razão das suas atividades laborais relacionadas à prestação de serviços, não tinham condições de executá-las em suas casas, aprofundando os níveis de desemprego e de exclusão social. As entregas e os deliverys, por força de decretos federais, estaduais e municipais, foram considerados atividades essenciais, motivo pelo qual os entregadores e motoboys não tiveram suas atividades suspensas, inclusive a demanda de serviços aumentou exponencialmente.

Pela necessidade de isolamento social decorrente da pandemia no país, grande parcela populacional passou a utilizar os serviços de delivery para o recebimento de produtos de diferentes seguimentos, como alimentação, farmácia e supermercado. Tal situação impulsionou o expressivo aumento do volume de entregas realizadas por trabalhadores, na grande maioria, autônomos que configurou a classe dos chamados entregadores de aplicativos inseridos na dinâmica do denominado capitalismo de plataforma.

A caracterização das atividades de entregas e congêneres como essenciais deu azo, entretanto, à precarização das condições de trabalhado dos entregadores, os quais, não abrangidos pelos direitos e garantias trabalhistas, foram preteridos pelos detentores do capital e desassistidos pelas autoridades governamentais. Emergiram, então, os movimentos sociais organizados pelos próprios entregadores, como o "Breque dos Apps", buscando melhores condições de trabalho e de vida a todos que se identificassem como integrantes da classe.

Vislumbra-se, porém, que os movimentos de paralisação ocorridos em 1 으 e 25 de julho de 2020 foram organizados pelos próprios entregadores, sem nenhuma participação de sindicatos ou de centrais sindicais, pois os próprios trabalhadores estavam na defesa de melhores condições de trabalho para a manutenção de sua subsistência e de suas famílias. Evidencia-se, assim, o descolamento dessa classe de trabalhadores do ideal de associação sindical consolidado a partir do século XIX com o desenvolvimento do capitalismo industrial e do trabalho assalariado. 
Os "Breques dos Apps" e a organização de trabalhadores denominada "Entregadores Antifascistas" denota a prevalência do direito de associação mais amplo resguardado pela Constituição Cidadã (art. 5o, incisos XVI a XX), mas evidencia, ainda, a fratura do modelo de representação sindical brasileiro que se fragilizou com a "Reforma Trabalhista" de 2017 e se agrava em tempos pandêmicos. Conforme já referenciado, embora a Lei no 13.467/2017 apregoasse a adoção da intervenção mínima do Poder Judiciário nas negociações trabalhistas (art. 8o, §3으, CLT) ante a valorização das normas autônomas, isso não se confirmou em diversos dispositivos alterados no texto consolidado outrora analisados, contrariando, inclusive, diretrizes da Constituição.

A desvalorização do papel dos sindicatos se agravou com a Reforma de 2017 e possibilitou, por via reflexa, o sufocamento do direito de livre associação sindical como se vislumbra nos movimentos dos entregadores de aplicativos que preferiram se organizar sozinhos, sem a intermediação de sindicatos, na defesa de direitos laborais e sociais, em nítido exercício de seu direito de resistência.

Embora a manutenção de um diálogo social entre trabalhadores, empregadores, sociedade e Estado se mostre salutar e necessária no Estado Democrático Social e de Direito, o modelo sindical brasileiro está seriamente ameaçado, inclusive já havendo o afastamento de trabalhadores do vínculo sindical, como é o caso dos entregadores de aplicativos que preferiram reivindicar seus direitos sem a intermediação sindical durante pandemia a fim de garantir a própria subsistência. A ausência do sentimento de representatividade pelos entregadores vinculados às empresasaplicativo é um indicativo da fratura do sistema representativo.

Como outrora afirmado, a livre associação sindical é direito humano e fundamental e a participação sindical nas negociações coletivas é fundamental para a efetividade dos direitos laborais, porém, não se é possível desconsiderar esses movimentos sociais dos entregadores de aplicativo que sozinhos buscaram melhores condições de trabalho a fim de viabilizar a concretude do trabalho digno.

Tal situação pode "transbordar" para outras classes de trabalhadores afastando ainda mais a representação sindical das relações de trabalho, principalmente nesse momento de fragilização humana e social decorrente da pandemia de coronavírus. Nesse sentido, os sindicatos precisam se reinventar a fim de manterem seu protagonismo na representação dos trabalhadores e nas 
negociações coletivas na atual conjuntura brasileira e mundial, caso contrário, seu papel, antes primordial na defesa dos direitos laborais, estará seriamente ameaçado.

\section{REFERÊNCIAS}

ABBAGNANO, Nicola. Dicionário de filosofia. Revisão da tradução e tradução dos novos textos Ivone Castilho Benedetti. 5. ed. São Paulo: Martins Fontes, 2007, p. 1147-1148.

ABÍLIO, Ludmila Costhek; ALMEIDA, Paula Freitas de; AMORIM, Henrique; CARDOSO, Ana Cláudia Moreira; FONSECA, Vanessa Patriota da; KALIL, Renan Bernardi; MACHADO, Sidnei. Condições de trabalho de entregadores via plataforma digital durante a COVID-19. Revista Jurídica Trabalho e Desenvolvimento Humano, v. 3, 8 jun. 2020.

ABÍLIO, Ludmila Costhek; ALMEIDA, Paula Freitas de; AMORIM, Henrique; CARDOSO, Ana Cláudia Moreira; FONSECA, Vanessa Patriota da; KALIL, Renan Bernardi; MACHADO, Sidnei. Condições de trabalho em empresas de plataforma digital: os entregadores por aplicativo durante a Covid-19. São Paulo: REMIR, 2020.

ANTUNES, Ricardo; ALVES, Giovanni. As mutações no mundo do trabalho na era da mundialização do capital. Educação e Sociedade, v. 25, n. 87, p. 335-351, mai./ago. 2004.

CATHARINO, José Martins. Tratado elementar de direito sindical: doutrina, legislação. São Paulo: LTr, 1977.

CRAVO, Patrícia Benetti; CORREIA, Sandra Cristina Zanoni Cembraneli. Terceirização e precarização do trabalho. In: LORA, Ilse Marcelina Bernardi; SLOMP, Angélica Cândido Nogara; GARCIA, Alessandra Souza (org.). Reforma trabalhista: um necessário olhar feminino. São Paulo: Tirant lo Blanch, 2019.

DELGADO, Gabriela Neves; AMORIM, Helder Santos. A legislação pandêmica e o perigoso regime de exceção aos direitos fundamentais trabalhistas. Revista Jurídica Trabalho e Desenvolvimento Humano, v. 3, 29 set. 2020.

DELGADO, Mauricio Godinho. Curso de direito do trabalho. 16 ed. São Paulo: LTr, 2017.

DUDIUK, Pedro e PRADO, Silvio. Introdução. In: AMARAL, Fernanda Pattaro et. al. (Comp.). EI desangramiento latinoamericano: un panorama político contemporáneo sobre la reorganización y la reconfiguración del estado neoliberal. Barranquilla: Corporación Universitaria Americana, 2018.

FERRAJOLI, Luigi. Por uma teoria dos direitos e dos bens fundamentais. Trad. Alexandre Salim e outros. Porto Alegre: Livraria do Advogado Editora, 2011. 
GROHMANN, Rafael; ALVES, Paula. É luta de classes mesmo, sem conversinha: entrevista com Galo, dos Entregadores Antifascistas. Digilabour, $2020 . \quad$ Disponível em: $<$ https://digilabour.com.br/2020/07/02/e-luta-de-classes-mesmo-sem-conversinha-entrevistacom-galo-dos-entregadores-antifascistas/>. Acesso em: 10. ago. 2020.

ITAMARATY. Declaração Sociolaboral do MERCOSUL de 2015. Disponível em: $<$ http://www.itamaraty.gov.br/pt-BR/notas-a-imprensa/10519-declaracao-sociolaboral-domercosul-de-2015-i-reuniao-negociadora-brasilia-17-de-julho-de-2015> . Acesso em: 20 mai. 2020.

KALIL, Renan Bernardi. Capitalismo de plataforma e direito do trabalho: crowdwork e trabalho sob demanda por meio de aplicativos. Tese de Doutorado. Universidade de São Paulo (USP), Programa de Pós-Graduação em Direito, 2019, 366 f.

MAGANO, Octávio Bueno. Manual de direito do trabalho. São Paulo: LTr, 1992.

MAIOR, Jorge Luiz Souto. Curso de direito do trabalho: teoria geral do direito do trabalho, v. 1, parte 1, São Paulo: LTr, 2011.

MARCONI, Marina de Andrade; LAKATOS, Eva Maria. Metodologia científica. 5 ed. São Paulo: Atlas, 2003.

MARTINS, Juliane Caravieri. Trabalho digno e direitos humanos em tempos de globalização: perspectivas para a América Latina. Belo Horizonte: Arraes Editores, 2017.

ORGANIZAÇÃO DOS ESTADOS AMERICANOS (OEA). Carta democrática interamericana. Disponível em: <http://www.oas.org/OASpage/port/Documents/Democractic Charter.htm>. Acesso em: 07 jul. 2020.

ORGANIZAÇÃO INTERNACIONAL DO TRABALHO (OIT). Ratificaciones por convenio. Disponível em <https://www.ilo.org/dyn/normlex/es/f?p=NORMLEXPUB:12001:0::NO>. Acesso em: 26 mar. 2020.

SARLET, Ingo Wolfgang. Os direitos fundamentais sociais na Constituição de 1988. Revista Diálogo Jurídico. a. I, v. I, n. 1, Salvador, abril de 2001, p. 01-46.

SILVA, Sidartha Sória e. Reestruturação produtiva, crise econômica e os rumos do sindicalismo no Brasil. Brasília: Faculdade Milton Campos, Conselho de Reitores das Universidades Brasileiras, 2001.

SUPIOT, Alain. Homo juridicus: ensaio sobre a função antropológica do direito. Trad. Maria Ermantina de Almeida Prado Galvão. São Paulo: WMF Martins Fontes, 2007.

SUSSEKIND, Arnaldo. Direito internacional do trabalho. 3. ed. atual. São Paulo: LTr, 2000. 
THOMPSON, Edward Palmer. A formação da classe operária inglesa: a maldição de adão. Trad. Renato Busatto Neto e Claudia Rocha de Almeida. v. 2, 2 ed. Rio de Janeiro: Paz e Terra, 1997.

UNIVERSIDADE DE SÃO PAULO (USP). Biblioteca virtual de direitos humanos. Disponível em: <http://www.direitoshumanos.usp.br/>. Acesso em: 07 jul. 2020. 